Article

\title{
Spatiotemporal Variations of Precipitation over Iran Using the High-Resolution and Nearly Four Decades Satellite-Based PERSIANN-CDR Dataset
}

\author{
Hamidreza Mosaffa ${ }^{1}$, Mojtaba Sadeghi ${ }^{2}$, Negin Hayatbini ${ }^{2}{ }^{\circ}$, Vesta Afzali Gorooh ${ }^{2}{ }^{(0)}$, \\ Ata Akbari Asanjan 2,3, Phu Nguyen 2 (D) and Soroosh Sorooshian 2,4,* \\ 1 Water Engineering Department, Shiraz University, Shiraz 71964-84334, Iran; h.mosaffa@shirazu.ac.ir \\ 2 Center for Hydrometeorology and Remote Sensing (CHRS), The Henry Samueli School of Engineering, \\ Department of Civil and Environmental Engineering, University of California, Irvine, CA 92697, USA; \\ mojtabas@uci.edu (M.S.); nhayatbi@uci.edu (N.H.); vafzalig@uci.edu (V.A.G.); \\ aakbariasanjan@usra.edu (A.A.A.); ndphu@uci.edu (P.N.) \\ 3 Universities Space Research Association, Mountain View, CA 94043, USA \\ 4 Department of Earth System Science, University of California Irvine, 3200 Croul Hall, Irvine, \\ CA 92697-2175, USA \\ * Correspondence: soroosh@uci.edu
}

Received: 16 April 2020; Accepted: 13 May 2020; Published: 16 May 2020

\begin{abstract}
Spatiotemporal precipitation trend analysis provides valuable information for water management decision-making. Satellite-based precipitation products with high spatial and temporal resolution and long records, as opposed to temporally and spatially sparse rain gauge networks, are a suitable alternative to analyze precipitation trends over Iran. This study analyzes the trends in annual, seasonal, and monthly precipitation along with the contribution of each season and month in the annual precipitation over Iran for the 1983-2018 period. For the analyses, the Mann-Kendall test is applied to the Precipitation Estimation from Remotely Sensed Information using Artificial Neural Networks-Climate Data Record (PERSIANN-CDR) estimates. The results of annual, seasonal, and monthly precipitation trends indicate that the significant decreases in the monthly precipitation trends in February over the western (March over the western and central-eastern) regions of Iran cause significant effects on winter (spring) and total annual precipitation. Moreover, the increases in the amounts of precipitation during November in the south and south-east regions lead to a remarkable increase in the amount of precipitation during the fall season. The analysis of the contribution of each season and month to annual precipitation in wet and dry years shows that dry years have critical impacts on decreasing monthly precipitation over a particular region. For instance, a remarkable decrease in precipitation amounts is detectable during dry years over the eastern, northeastern, and southwestern regions of Iran during March, April, and December, respectively. The results of this study show that PERSIANN-CDR is a valuable source of information in low-density gauge network areas, capturing spatiotemporal variation of precipitation.
\end{abstract}

Keywords: trend analysis; precipitation; satellite precipitation product; PERSIANN-CDR; Iran

\section{Introduction}

Precipitation is one of the important climatic variables whose variability has impacts on floods, droughts [1], and water availability [2]. This is especially important for arid and semi-arid regions such as Iran, with limited water availability [3] and many natural disasters including floods and droughts [4]. Therefore, investigating the variations in precipitation is necessary for decision-makers and stakeholders to manage water resources and natural hazards. 
Investigating precipitation variability requires reliable, long-term, and high spatiotemporal resolution precipitation information. Several studies have been conducted to investigate global precipitation variations at global and local scales using different precipitation estimation datasets [5-13]. Previous studies over Iran attempted to analyze the precipitation trends at annual, seasonal, and monthly scale using a limited number of gauge network datasets obtained from synoptic weather stations of Meteorological Organization of Iran with at least 30-year records (Table 1). Table 1 summarizes a literature review of precipitation trend analyses in parts of or throughout Iran, as well as detailed information such as the number of weather stations used and their results. The inadequacy and the sparsity of gauge networks tend to undermine their applicability and increase the uncertainties in their findings. Satellite-based precipitation information is a suitable alternative to sparse gauge networks because of the nearly four decades' records and high-resolution data. Precipitation Estimation from Remotely Sensed Information using Artificial Neural Networks-Climate Data Record (PERSIANN-CDR) [14] is an operational satellite product with quasi-global coverage, providing one of the longest data records among the satellite-based products (from 1983 to present). PERSIANN-CDR is a daily product with a spatial resolution of $0.25^{\circ}$ [14]. The modified PERSIANN algorithm $[15,16]$ and the Global Precipitation Climatology Project (GPCP) $2.5^{\circ}$ monthly data, which include GPCC gauge information, are used to produce PERSIANN-CDR, while PERSIANN-CDR provides higher spatial and temporal resolution precipitation in comparison with GPCP [17]. Many studies with requirements of high spatial and long-term precipitation datasets used PERSIANN-CDR for different applications such as trend analysis ([18] (Amazon Basin); [7] (global); [19] (China); [11] (over part of India); [20] (over part of Brazil)) and drought monitoring [21-26]. Various studies have evaluated the performance of the PERSIANN-CDR estimates over Iran [27-35]. Katiraie-Boroujerdy et al. [27] evaluated the PERSIANN-CDR daily precipitation using the information of about 1000 rain gauges during the period of 1998-2007 over Iran. Their results showed that PERSIANN-CDR had a considerable correlation of coefficients in the western region of Iran and performed well to distinguish rain from no-rain condition, particularly in the southwest region, which is in agreement with Alijanian et al. [28]. Moreover, the result assessment of daily PERSIANN-CDR precipitation over southern slopes of Alborz Mountains in north of Iran by Khalighi-Sigaroodi et al. [29] showed that the probability of detection of the precipitation events is around 0.8. Salmani-Dehaghi \& Samani [30] conducted evaluation of PERSIANN-CDR monthly precipitation over Fars province in south of Iran, They reported that correlation of coefficients of PERISANN-CDR ranges between 0.81 and 0.95 . Moreover, the value of correlation coefficient reported by Fallah et al. [31] is 0.88 for evaluation of PERSIANN-CDR against local observations over the southwestern part of Iran. A recent study by Mosaffa et al. [32] concluded that the daily PERSIANN-CDR dataset has the best performance in terms of probability of detection of the precipitation events among eight post and near real-time satellite precipitation products over western parts of Iran.

Although gridded precipitation datasets are used to capture the spatial pattern of precipitation at high resolution, only a few studies have used the PERSIANN-CDR dataset to investigate precipitation changes across Iran. In addition, these studies focused on analyzing the annual amounts of precipitation and extreme indices for the period before 2013. For example, Raziei et al. [36] and Balling et al. [37] used the APHRODITE gridded daily precipitation dataset with a spatial resolution of $0.5^{\circ} \times 0.5^{\circ}$ for the period 1961-2004 and 1951-2007, respectively. Their trend analysis is limited to trend analysis of annual total precipitation and daily precipitation indices, such as maximum daily precipitation, a number of rainy days in a year, and percent of annual precipitation from daily events $\geq 10 \mathrm{~mm}$. Their results indicate that significant trends in these indices occur mainly in western and southwestern Iran. In addition, Katiraie-Boroujerdy et al. [27] used satellite-based precipitation PERSIANN-CDR with $0.25^{\circ}$ spatial resolution to trend analysis of annual precipitation, the number of rainy days, and precipitation extremes over Iran. Their results show that annual precipitation has downward trends over the western and eastern regions of Iran, while the annual number of rainy days have upward trends over the northern and northwestern regions. This work has focused on the period 1983-2012; 
however, during the last couple of years, we have seen many extreme events in both precipitation and drought over Iran [4], indicating that there is a need to investigate these variations for the periods after 2013.

In arid and semi-arid regions, the temporal distribution of annual precipitation is crucial for water resources management and irrigation planning. For this purpose, over Iran, Khalili et al. [38] calculated a precipitation concentration index (PCI), which describes the degree of inter-annual precipitation variability. PCI does not include any information about the contribution of each month and season to annual precipitation separately and no study to date has been carried out to investigate this issue in Iran. So, the overarching goals of this study are as follows: (1) to investigate the trends in annual, seasonal, and monthly precipitation over Iran, and (2) to investigate the trends in the contribution of each season and month in the total annual precipitation for the period of 1983-2018 over Iran. The PERSIANN-CDR dataset with $0.25^{\circ}$ spatial resolution is adapted as precipitation estimation and the Mann-Kendall non-parametric test is used for trend investigation.

Table 1. Summary of literature review of the precipitation trend analysis in Iran.

\begin{tabular}{|c|c|c|c|c|}
\hline References & \# Weather Stations & Study Period & Study Area & Key results \\
\hline [39] & 20 & 1955-2000 & Arid and semi-arid regions & Significant trend in two stations \\
\hline$[41]$ & 26 & 1951-2005 & Throughout Iran & $\begin{array}{l}\text { Significant negative trend in three stations, which } \\
\text { observed in the northwest }\end{array}$ \\
\hline [44] & 33 & 1951-2005 & Throughout Iran & Significant negative trend in five stations \\
\hline [45] & 50 & 1950-2007 & Southwestern & Significant positive trend in seven stations \\
\hline [38] & 34 & $1961-2010$ & Throughout Iran & Significant negative trend in eight stations \\
\hline [46] & 18 & $1951-2010$ & Throughout Iran & Significant negative trend in five stations \\
\hline [47] & 40 & 1967-2014 & Throughout Iran & $\begin{array}{l}30.5 \% \text { of the country has been significant } \\
\text { decreased }\end{array}$ \\
\hline$[43]$ & 28 & $1967-2006$ & East, central, and north & $\begin{array}{l}\text { Significant negative trends in five stations in the } \\
\text { winter observed mostly in northern }\end{array}$ \\
\hline [45] & 50 & 1950-2007 & Southwestern & No significant trends were detected in summer \\
\hline \multirow[t]{2}{*}{ [38] } & 34 & 1961-2010 & Throughout Iran & $\begin{array}{l}\text { Significant negative trend spring and winter in } \\
\text { six stations, one station in summer }\end{array}$ \\
\hline & & \multicolumn{3}{|c|}{ Monthly precipitation } \\
\hline [39] & 20 & 1955-2000 & Arid and semi-arid regions & $\begin{array}{l}\text { Four stations with significant positive trends in } \\
\text { March and significant negative trends in April in } \\
\text { four stations }\end{array}$ \\
\hline [41] & 26 & 1951-2005 & Throughout Iran & $\begin{array}{l}\text { The significant negative trends in most part of } \\
\text { Iran in months (June, July, and August) }\end{array}$ \\
\hline
\end{tabular}

The remainder of this paper is organized as follows. Sections 2 and 3 provide information on the study area and the methodology, respectively. Sections 4 and 5 present the trend analysis results and discussion, respectively. The main conclusions of this study are summarized in Section 6.

\section{Study Area}

Iran is located in southwest Asia $\left(44 \circ 05^{\prime} \mathrm{E}-63 \circ 19^{\prime} \mathrm{E} ; 25 \circ 03^{\prime} \mathrm{N}-39 \circ 47^{\prime} \mathrm{N}\right)$ and covers an area of about $1,648,000 \mathrm{~km}^{2}$, of which approximately $88 \%$ is arid and semi-arid [4] (Figure 1a). Iran is bordered to the north by the Caspian Sea and to the south by the Persian Gulf and the Gulf of Oman. The climate of Iran is affected by different meteorological systems including Siberian high-pressure, Mediterranean, and low-pressure southern systems [38]. These systems are affected by the high spatial variation of elevation of two mountain ranges-Alborz in the north and Zagros in the west [44] - leading to the 
temporal and spatial variation of precipitation over the country. On the basis of the PERSIANN-CDR datasets (1983-2018), the mean annual precipitation of Iran is $264.7 \mathrm{~mm}$.

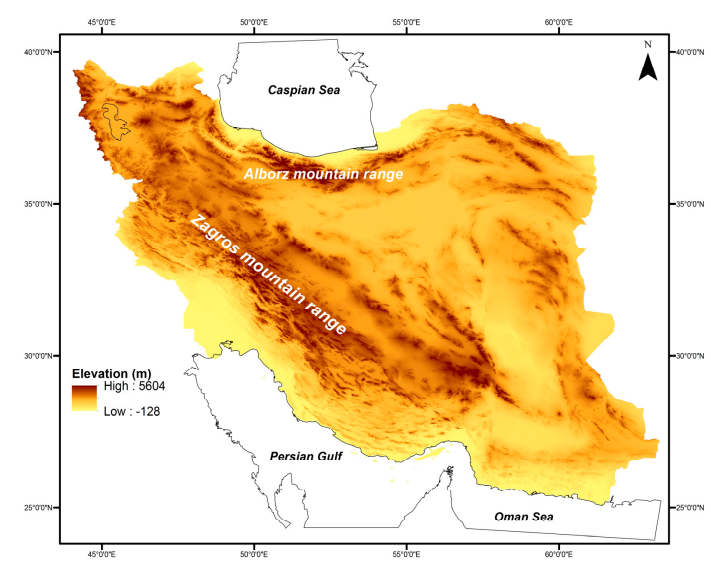

(a)

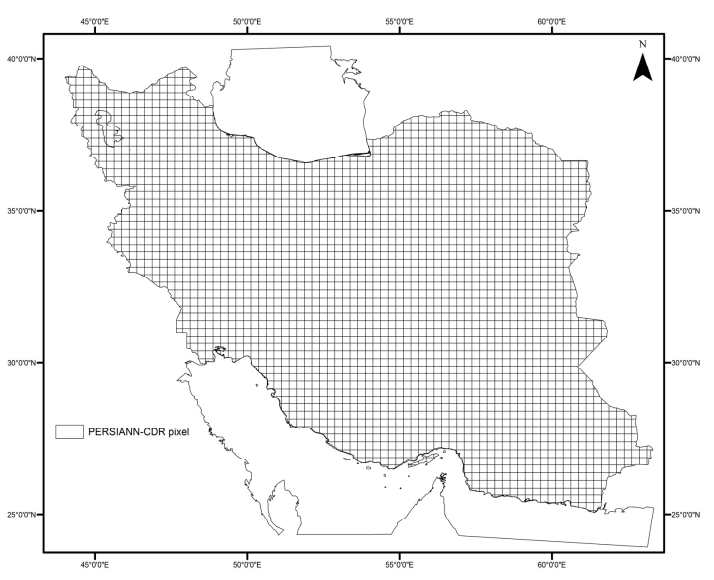

(b)

Figure 1. (a) Topographic map of Iran; (b) grid pixels of Precipitation Estimation from Remotely Sensed Information using Artificial Neural Networks-Climate Data Record (PERSIANN-CDR).

\section{Data and Methodology}

\subsection{Data}

The Precipitation Estimation from Remotely Sensed Information using Artificial Neural Networks-Climate Data Record (PERSIANN-CDR) product was developed by the Center for Hydrometeorology and Remote Sensing (CHRS) at the University of California, Irvine (UCI). The PERSIANN-CDR dataset provides daily near-global precipitation estimates with $0.25^{\circ} \times 0.25^{\circ}$ spatial resolution from 1983 to the present. The PERSIANN-CDR algorithm uses an artificial neural network (ANN) model to convert gridded satellite (GridSat-BI) infrared information [48,49] as an input into the rain rates retrieved. The National Centers for Environmental Prediction (NCEP) Stage IV hourly precipitation $[50,51]$ is utilized for creating the non-linear regression parameters of the ANN model. The estimates of the ANN model are bias-adjusted with the Global Precipitation Climatology Project (GPCP) monthly product with $2.5^{\circ} \times 2.5^{\circ}$ spatial resolution at a monthly time scale. The PERSIANN-CDR dataset is available via the NOAA National Centers for Environmental Information (NCEI) Program (https://www.ncdc.noaa.gov/cdr) and via the CHRS Data Portal (http://chrsdata.eng.uci.edu/, [52]). A comprehensive description of the PERSIANN-CDR algorithm can be found in Ashouri et al. [14]. In the current study, the PERSIANN-CDR product for the period ranging from 1983 to 2018 was used for the trend analysis.

\subsection{Data Processing}

As shown in Figure 1b, there are 5604 pixels of PERSIANN-CDR within Iran's boundary. The trend analysis is done for each pixel and different temporal scales, including annual, seasonal, and monthly precipitation. For this purpose, the monthly datasets of each pixel are downloaded, then converted to the seasonal and annual data. The seasons are defined as follows: winter (December-February), spring (March-May), summer (June-August), and fall (September-November). To understand the seasonal variations, we investigate the trend in the contribution of each season and month to annual precipitation. These contributions are calculated by dividing the seasonal and monthly precipitation values by the corresponding annual precipitation value, respectively. Moreover, for precise investigation, the average percentage of each seasonal and monthly contribution in annual precipitation is analyzed in wet and 
dry years separately. Wet and dry years are selected with respect to the years with a 12-month SPI (standardized precipitation index) of $>1$ and $<-1$, respectively [53].

\subsection{Trend Analysis}

The nonparametric Mann-Kendall [54,55] test has been widely applied to investigate the trends in precipitation using different datasets $[7,38,40,43]$. This test is a useful method for this purpose because it allows for missing values and the data are not required to be from a normal distribution. According to this test and under the null hypothesis $\left(\mathrm{H}_{0}\right)$, data are independent and there is no trend. The alternative hypothesis, $\mathrm{H}_{1}$, is that the data have a trend. The Mann-Kendall test starts with calculating the statistic $S$. In this study, the time series of precipitation in each pixel is used to calculate the statistic $S$ as follows:

$$
S=\sum_{k=1}^{n-1} \sum_{j=k+1}^{n} \operatorname{sgn}\left(x_{j}-x_{k}\right),
$$

where $\mathrm{n}$ represents the total number of data in time series, $x_{j}$ and $x_{k}$ are the $\mathrm{j}^{\text {th }}$ and $\mathrm{k}^{\text {th }}$ value of the precipitation time series in chronological order, and the sign function is defined as follows:

$$
\operatorname{sgn}\left(x_{j}-x_{k}\right)= \begin{cases}+1 & \text { if }\left(x_{j}-x_{k}\right)>0 \\ 0 & \text { if }\left(x_{j}-x_{k}\right)=0, \\ -1 & \text { if }\left(x_{j}-x_{k}\right)<0\end{cases}
$$

when $\mathrm{n} \geq 8$, the distribution of statistic $S$ approaches the normal form with mean $(\mathrm{E}(\mathrm{S}))$ and variance (Var(S)) defined as follows:

$$
\begin{gathered}
E(S)=0, \\
\operatorname{Var}(S)=\frac{n(n-1)(2 n+5)-\sum_{i=1}^{m} t_{m}\left(t_{m}-1\right)\left(2 t_{m}+5\right)}{18},
\end{gathered}
$$

The second part of Equation $(4)\left(\sum_{i=1}^{m} t_{m}\left(t_{m}-1\right)\left(2 t_{m}+5\right)\right)$ is used only when data series contain successive data with same value (tied values). In this equation, $\mathrm{m}$ is the number of tie group and $t_{m}$ is the length of $m^{\text {th }}$ group. Finally, the standardized test statistic $Z$ is computed using Equation (1) and Equation (4) as follows:

$$
Z= \begin{cases}\frac{S-1}{\sqrt{\operatorname{Var}(S)}} & \text { if } S>0 \\ 0 & \text { if } S=0 \\ \frac{S+1}{\sqrt{\operatorname{Var}(S)}} & \text { if } S<0\end{cases}
$$

The statistic $Z$ is used as a measure of singnificant of trend by testing the null hypothesis. The null hypothesis $\mathrm{H}_{0}$ is rejected when $|Z|>Z_{1-\frac{\alpha}{2}}$ and, in this hypothesis, the existence of a significant trend is accepted. $\alpha$ denotes the chosen significant level, which is considered as 0.05 in this study. Moreover, the negative and positive values of $\mathrm{Z}$ indicate the decreasing and increasing trend, respectively.

\section{Results and Discussion}

\subsection{Annual Trend Analysis}

Figure 2 shows the spatial distribution map of annual precipitation trends using the PERSIANN-CDR estimates for the period from 1983 to 2018. In this figure, the statistically significant $(95 \%)$ positive and negative trends are in blue and red, respectively, and non-statistically significant trends are shown in white. There are limited numbers of pixels showing statistically significant changes in the annual precipitation over Iran. The annual precipitation decreased in the western (including Khuzestan, Ilam, Lorestan, Kermanshah, Hamadan, and Kurdistan provinces) and eastern (including some regions over Khorasan-jonoubi, Kerman, and Razavi Khorasan provinces) regions. On the 
other hand, the annual precipitation has increased significantly in small regions of northwestern Iran (including some area around Ardabil) and in a few pixels in the central part of the country.

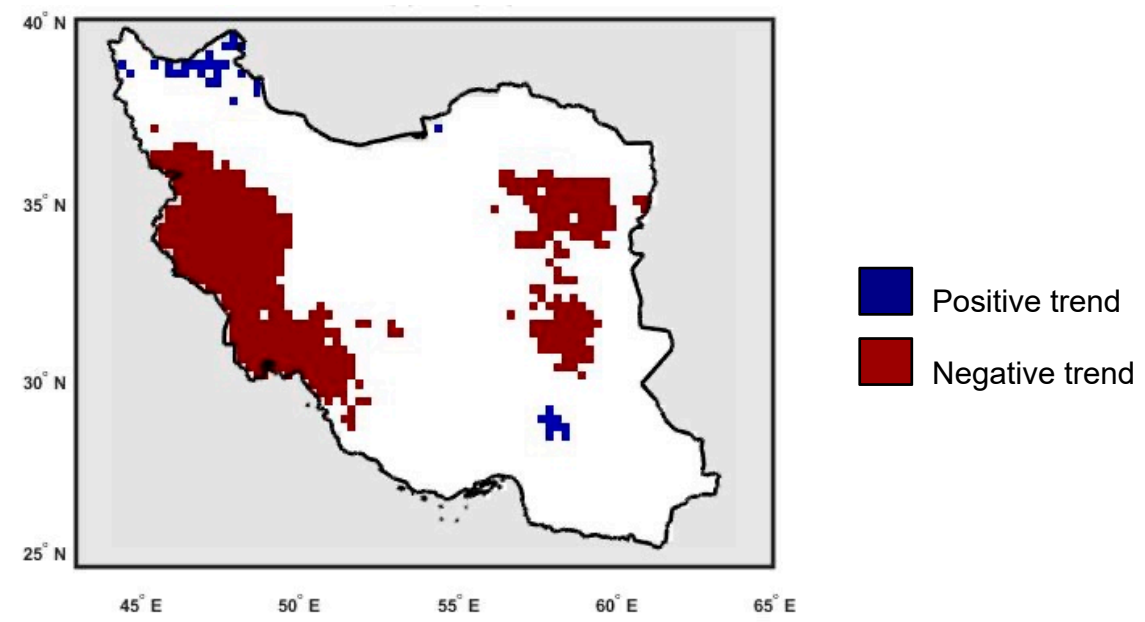

Figure 2. The spatial distribution map of trends in the annual precipitation based on PERSIANN-CDR for the period 1983-2018.

\subsection{Seasonal Trend Analysis}

Figure 3a displays the spatial distribution of the mean seasonal precipitation over Iran for the period 1983 to 2018 using the PERSIANN-CDR estimates. The results indicate that mountainous areas of Alborz, the coast of the Caspian Sea in Northern Iran, and western mountainous regions of the country (The Zagros Mountains) are the wettest regions. On the other hand, central, eastern, and southern regions of Iran are classified as the driest regions. Across the whole country, the highest amounts of precipitation occur during winter, while relatively identical precipitation patterns with lower rain rates are received during spring. Summer and fall are dry seasons, particularly in the central, eastern, and southern regions. The monsoon precipitation that occurs during summer in the arid region of the south-east is well captured by PERSIANN-CDR estimates.

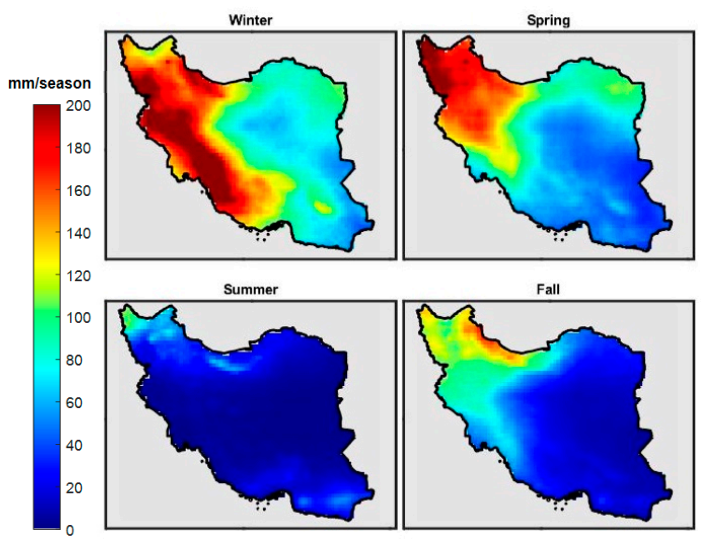

(a)

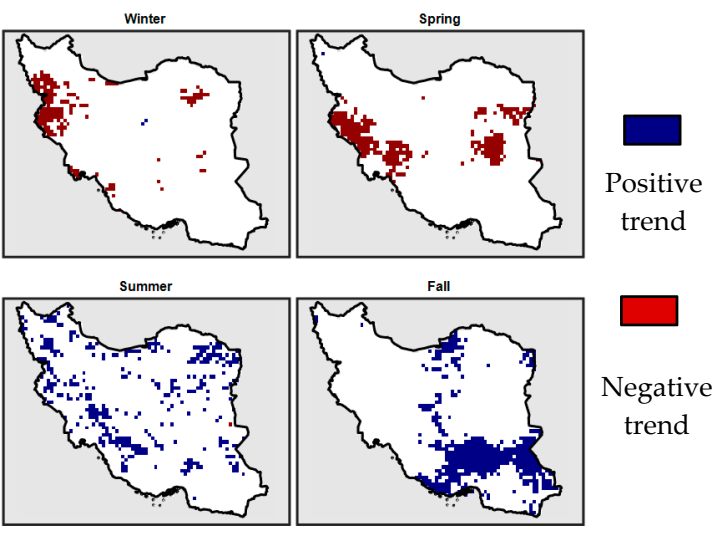

(b)

Figure 3. (a) Spatial patterns of mean seasonal precipitation in millimeters for the period 1983 to 2018; (b) spatial distribution map of trends in the seasonal precipitation based on PERSIANN-CDR for the same period.

Figure $3 \mathrm{~b}$ shows the spatial distribution of trends in the seasonal precipitation based on the PERSIANN-CDR estimates for the period from 1983 to 2018. The figure shows that winter precipitation is decreasing in small regions over western Iran, and this trend is statistically significant. Similarly, 
spring precipitation exhibits a statistically downward trend in small areas over the western and central-eastern regions of the country. The spatial pattern of the Mann-Kendall test for summer displays an upward trend in precipitation for different parts of Iran. In addition, a statistically significant upward trend is detectable over the south-eastern regions during the fall.

Figure $4 \mathrm{a}$ indicates the spatial contribution map of each season to the annual precipitation based on the climate data record of PERSIANN-CDR. The map is calculated by averaging the precipitation contribution of each season in annual rainfall for the period from 1983 to 2018. The results display that central, southern, and western Iran receive most of the annual rainfall during winter. On the contrary, northern and northwest Iran receive the same amounts of rainfall during fall, spring, and winter. The spatial pattern of the trend in the contribution of each season to annual precipitation is shown in Figure $4 \mathrm{~b}$. The statistically downward trend is only detectable over small regions in central Iran during spring. In contrast, the statistically upward trend can be seen along the Zagros Mountain and northeast Iran during summer and over the south-eastern regions during fall. Moreover, the south-eastern regions of Iran, whose contribution during fall is about $5 \%$ to $15 \%$ of the total annual precipitation, have a statistically significant upward trend. Moreover, except for a few pixels, no statistically significant trends can be observed in the contribution of the winter season to annual precipitation.

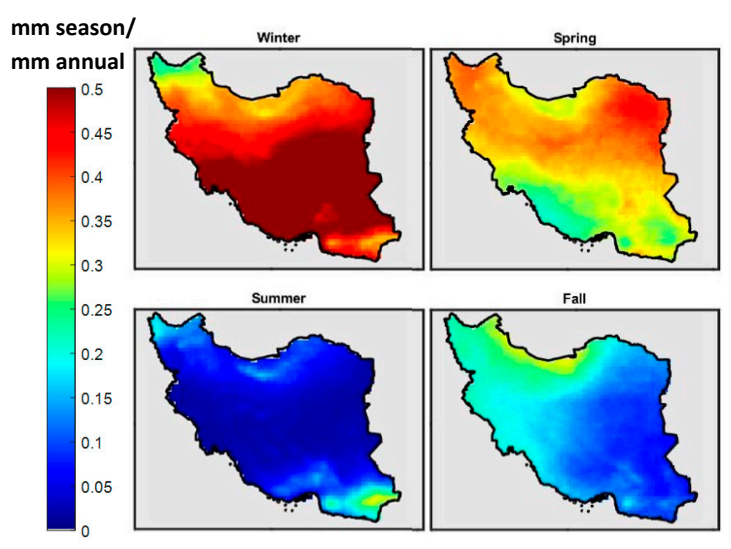

(a)

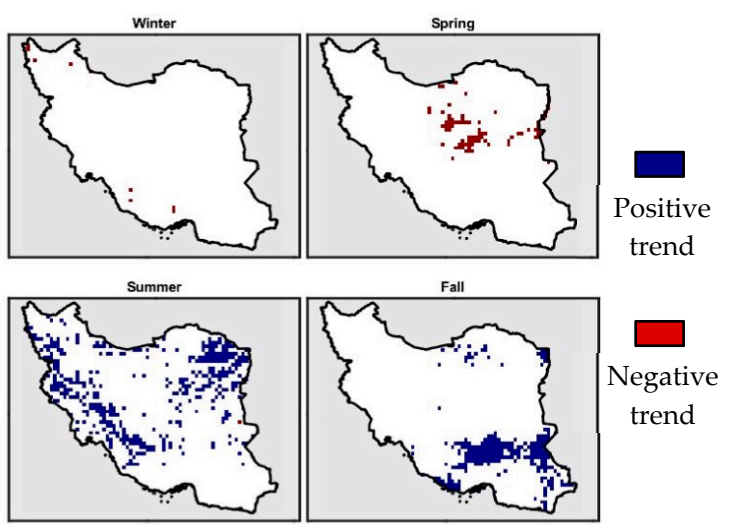

(b)

Figure 4. (a) Spatial contribution map for each season to annual precipitation based on the climate data record of PERSIANN-CDR for the period 1983 to 2018; (b) spatial map for trend of the contribution of each season to annual precipitation.

Figure 5 illustrates the spatial contribution map for each season to annual precipitation based on climate data record of PERSIANN-CDR for dry and wet years. The results show that mostly the central, southern, and eastern regions receive more than half of winter rainfall for both dry and wet years. However, the northeast of Iran receives more than half of the annual rainfall during winter in dry years and during spring in the wet years. The contribution of precipitation occurrence of both winter and spring is important for the total rainfall over the northwest of the country.

\subsection{Monthly Trend Analysis}

The mean monthly precipitation in each pixel is shown in Figure 6a. The figure shows that, same as seasonal precipitation, a mountain range in the west and north gets most of the monthly precipitation. The regions with the highest precipitation have stretched over the southwest-northwest from December to May. Moreover, the precipitation occurs over the north and southeast of Iran from July to September. The blue and red pixels in Figure $6 \mathrm{~b}$ refer to positive and negative statistically significant trends of mean monthly precipitation at the $95 \%$ confidence levels, respectively. Statistically negative significant trends occur in four months (December, January, February, and March). The eastern region is characterized by significant negative trends in December and January. Moreover, a downward 
significant trends is shown in the western region (including Kermanshah, Kordestan and parts of Orumieh provinces) in February. Furthermore, the results of March precipitation trends test show significant negative trends in the western (including Ilam, Lorestan, Hamadan and some regions of Arak provinces) and eastern (including some region of Khorasan-jonoubi and Yazd provinces) regions of Iran. In all summer months, the positive trend is detected in different regions like the north and central area in July. The results of the Mann-Kendall test of fall months show that, in most parts of Iran, except the south (in September), central, and southeast region (in October), and south southeast regions of Iran (including Hormozgan, Kerman, Sistan, and Baluchestan, and part of Fars provinces) (in November), have a significant increase.
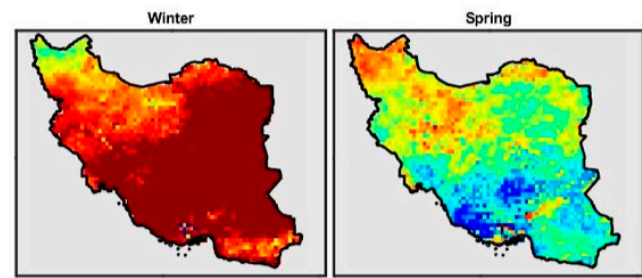

Summer
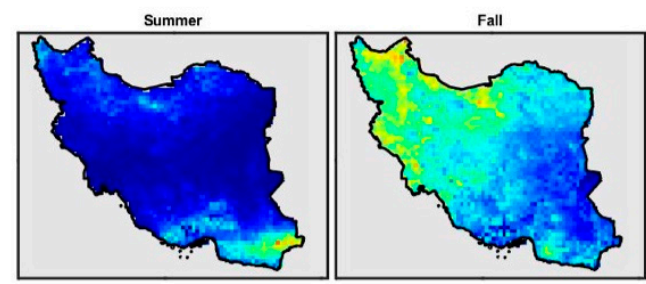

(a)
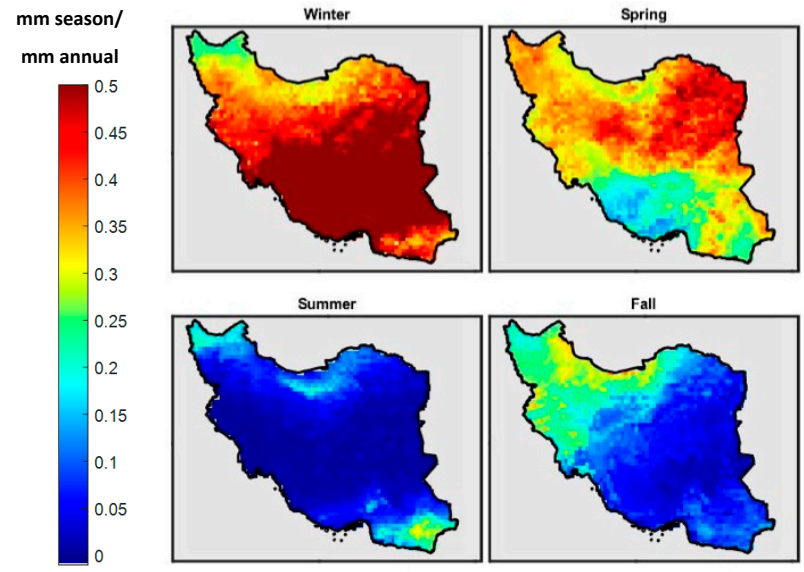

(b)

Figure 5. Spatial contribution map for each season in annual precipitation based on climate data record of PERSIANN-CDR for (a) dry and (b) wet years.

(a)

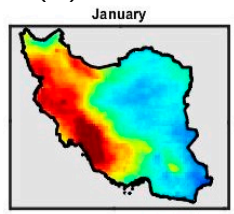

April
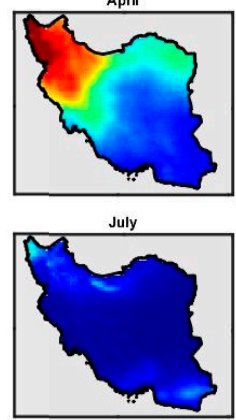

October

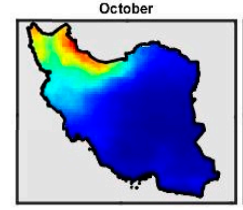

February

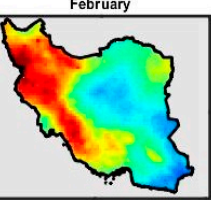

May
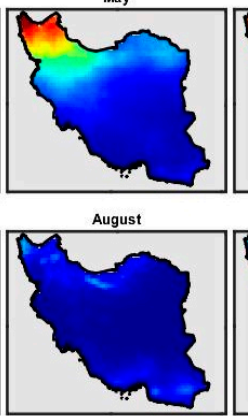

November

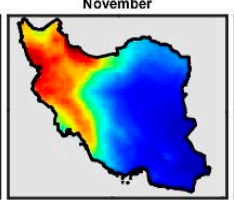

(b)

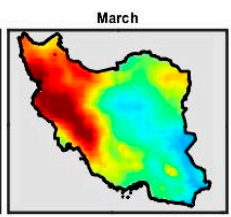

June
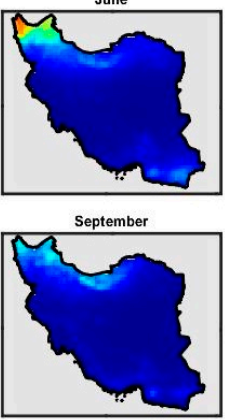

December

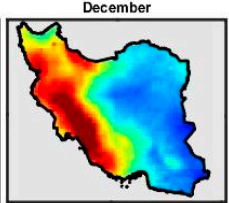

(b)
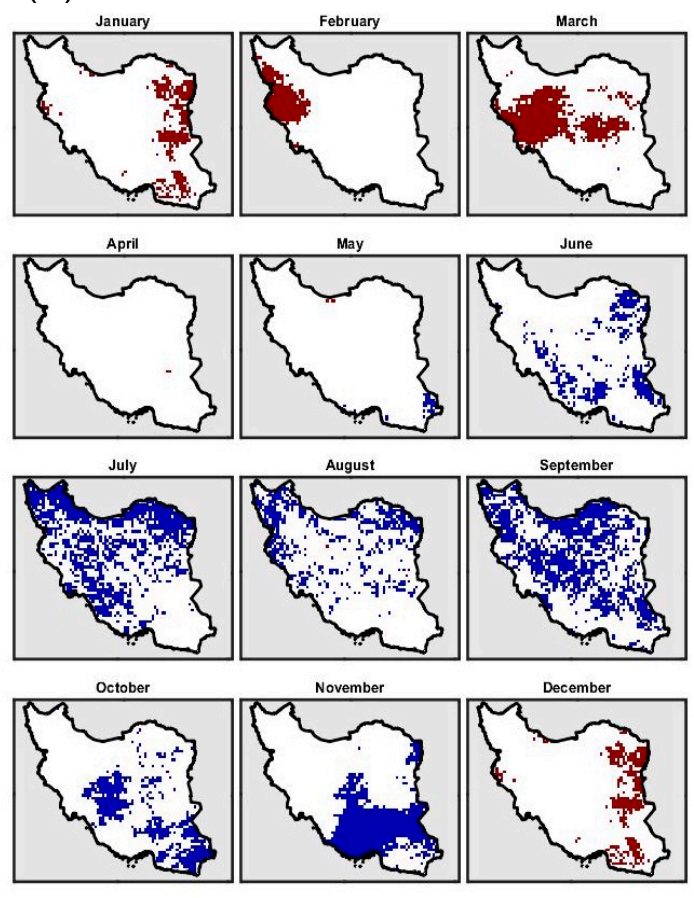

Positive trend

Figure 6. (a) Average of monthly precipitation amount; (b) monthly trend analysis, blue and red part represent the positive and negative trend, respectively. 
Figure 7a presents the spatial distribution of the average percentage of each month's contribution to annual precipitation. The temporal distribution of precipitation in each pixel is different. For instance, the uniform distribution of precipitation occurs from November to May over the northern regions of Iran, while for other regions, the majority of precipitation falls in one or two months. Figure 8 depicts the contribution of each month's annual precipitation in dry and wet years separately. The results indicate that, in the south and southwest regions of Iran (including Fars, Bushehr, and part of Yazd provinces), most of the precipitation amounts occur in December in a wet year, while the highest percentage of precipitation is lost in this month in a dry year. Moreover, remarkable precipitation is detectable in the eastern (northeast) region in March (April) during wet years, while these amounts decrease in dry years. According to the Mann-Kendall test for trend analysis of the contribution of each month to annual precipitation (Figure $7 \mathrm{~b}$ ), there are significant negative trends in the central region of Iran in March. Moreover, statistically significant positive trends are observed in a different part of Iran, including east and northeast (in June), along Alborz and Zagros Mountain and northeast (in July), the small region of western and eastern (in August), most part of Iran especially central (in September), central and southeast (in October), and south and southeast (in November).

(a)

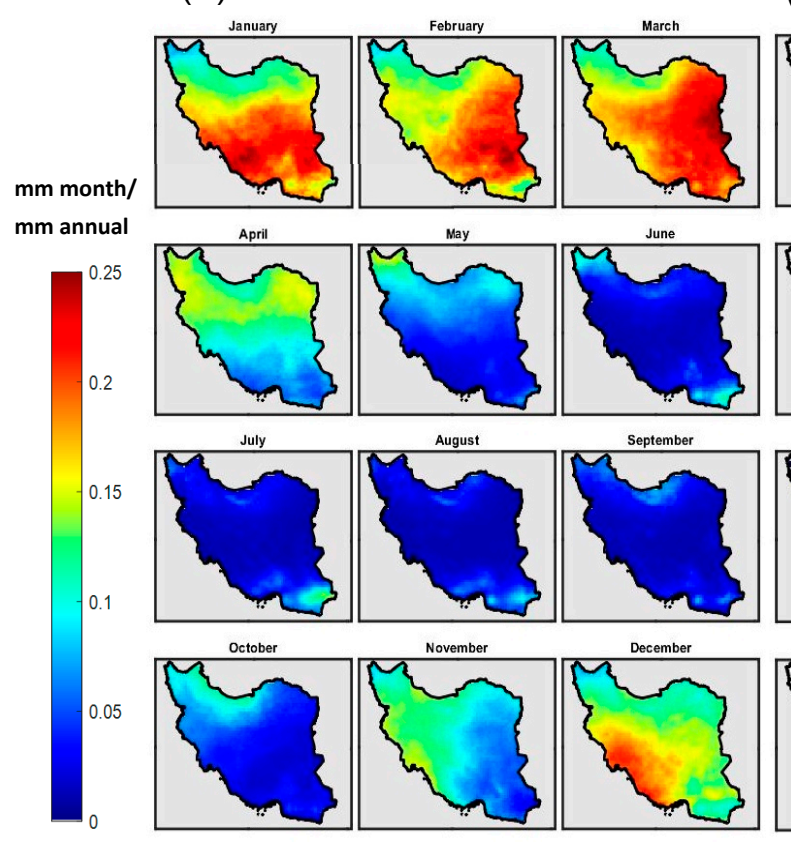

(b)
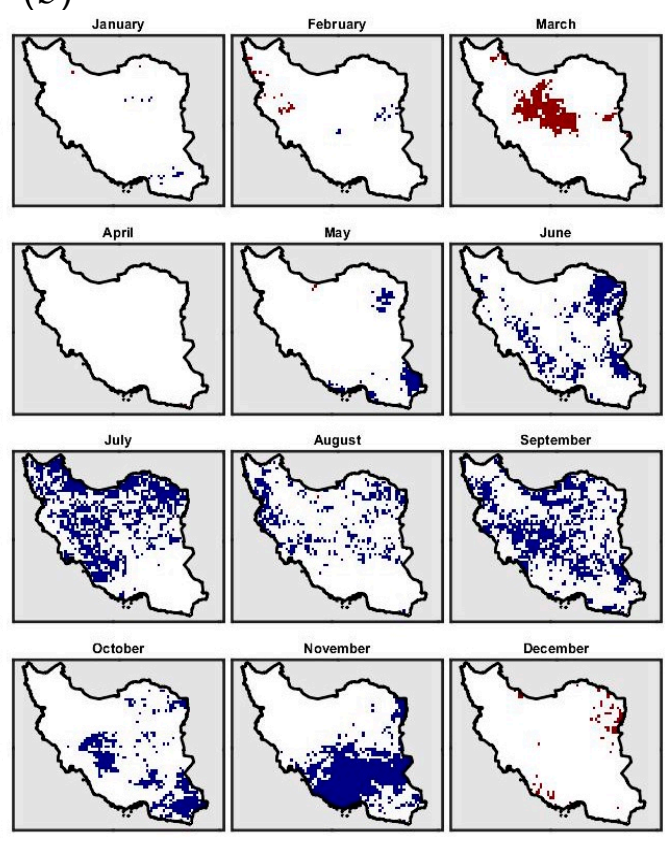

Positive trend

Negative trend

Figure 7. (a) Average percentage of each month contribution in annual precipitation; (b) monthly contribution trend analysis, blue and red part present the positive and negative trend, respectively.

\section{Discussion}

To investigate the trends in annual, seasonal, and monthly precipitation over Iran, PERSIANN-CDR dataset is used as precipitation estimation. The comparison results of the annual trend with seasonal trend indicated that the trends for winter and spring precipitation are similar to the annual trend, where we observe a statistically downward trend in western and central-eastern Iran. Moreover, a statistically significant upward trend over the south-eastern regions during the fall leads to a positive annual trend over a limited amount of pixels. Meanwhile, the positive trend in summer precipitation does not have any effect on annual precipitation. Furthermore, some monthly trends affect the trend in seasonal and annual precipitation. For instance, negative significant trends in the western region (including Kermanshah, Kordestan, and parts of Orumieh provinces) in February cause significant decreases in precipitation during winter, as well as in the annual precipitation in these regions. On the 
contrary, downward trends in December and January over the eastern region do not affect the trend in precipitation during winter (Figure $3 b$ ). In addition, as no significant trends are detected during the spring months except March over these regions, the downward spring significant trend is caused by March decreasing precipitation.

(a)

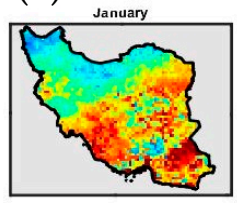

April

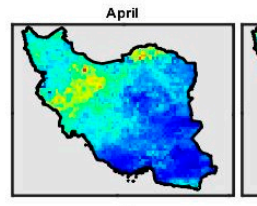

July

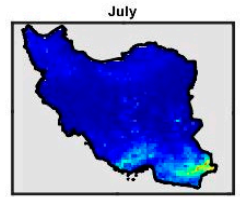

October

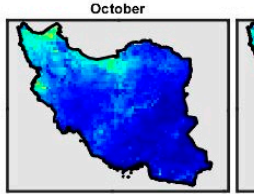

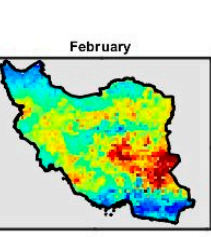

May

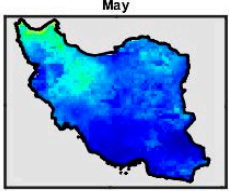

August
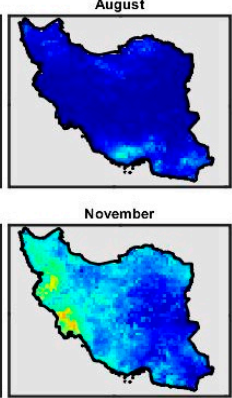

mm month/ mm annual

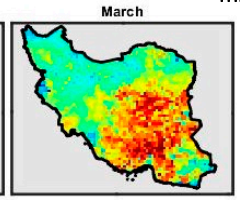

June

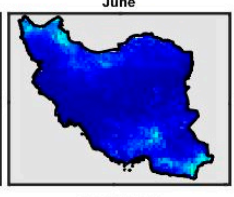

September
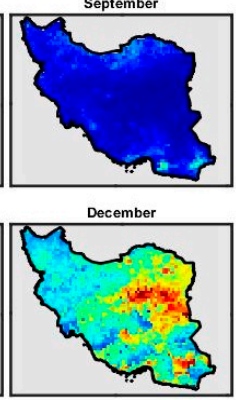

(b)
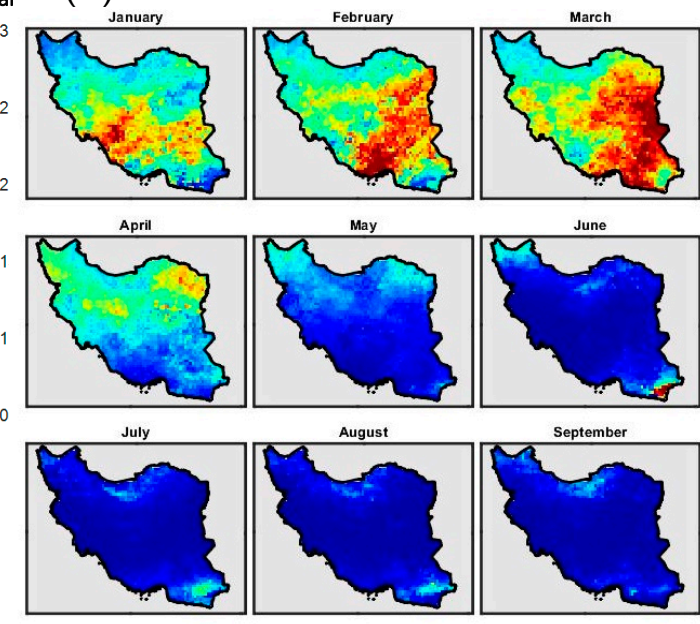

October

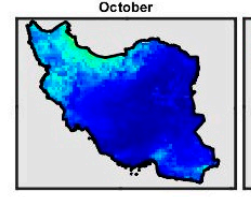

August
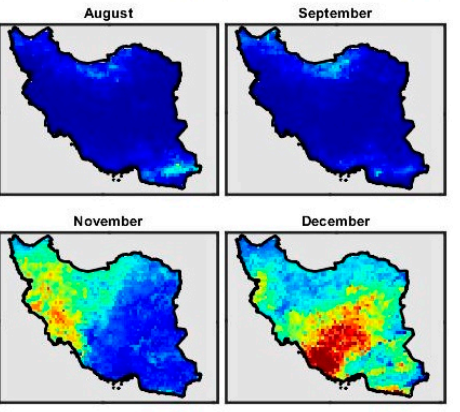

Figure 8. Average percentage of each monthly contribution in annual precipitation in (a) dry and (b) wet years.

Here, we compare our results with previous studies. The negative trend of annual precipitation in the western part of Iran was also reported by Tabari and Talaee [40]. Unlike the findings of some previous studies $[43,46]$, which showed negative trends in other parts of Iran such as northwestern Iran (including Tabriz, Oroomieh, and Saghez station), no significant trends are detected by our results over these regions. This discrepancy might be owing to the difference between the study periods. Furthermore, when comparing our results to those of previous studies, it must be pointed out that no comparison can be made over the regions that do not have any weather stations (such as trend positive over northwestern), because previous study results are limited to regions with weather stations. Moreover, according to Table 1, there are inconsistency between our results and pervious research at seasonal $([45])$ and monthly $([39,41,44])$ precipitation, which might be because of different study periods as well as different types of precipitation datasets (pixel-based and point gauge) used for trend analysis. Indeed, rain gauge measure precipitation in single point, while satellite product estimates precipitation over an area (pixel area).

Investigation of the trends in the contribution of each season and month in the total annual precipitation indicated that the positive trend in the contribution of fall to the annual precipitation over the south-eastern regions of Iran causes significant increasing precipitation in the fall season because both contributions for the fall in annual precipitation and fall seasonal precipitation have identical significant trend patterns. However, trends in the contribution of other season to annual precipitation do not affect the seasonal precipitation. Furthermore, there is no pixel over Iran significantly increasing in the contribution of a particular season to annual precipitation and a simultaneously significant decrease in other seasons, and vice versa. So, the contribution of any season to annual precipitation does not significantly shift to another season. 


\section{Conclusions}

Given the high spatial and temporal variations of precipitation in semi-arid regions like Iran, it is necessary for water decision-makers to analyze the precipitation patterns in these regions. In this study, the high spatial and temporal resolution PERSIANN-CDR dataset was used to analyze the precipitation at annual, seasonal, and monthly time scales over Iran for the period 1983-2018. Furthermore, trend analysis for the contribution of each season and month to the annual precipitation was conducted. The Mann-Kendall non-parametric test was applied for the trend analysis.

Both statistically upward and downward trends were observed in monthly precipitation. However, most of months do not have a significant effect on the seasonal and annual precipitation. Indeed, just February and March cause significant decreases in precipitation during winter and spring, respectively, and in the annual precipitation. Moreover, the upward fall significant trend is caused by November decreasing precipitation, while it does not have a remarkable effect on the annual precipitation. Seasonal trend analysis showed that the summation of a significant downward trend in winter and spring causes significant decreasing annual precipitation, while summer and fall trends do not display remarkable effects on annual precipitation. Finally, the result of the annual trend, which is affected by the monthly and seasonal trend, indicated that some parts of Iran have statistically significant negative trends, including the western regions (including Khuzestan, Ilam, Lorestan, Kermanshah, Hamadan, and Kurdistan provinces) and eastern regions of Iran (including some regions over South Khorasan, Kerman, and Razavi Khorasan provinces), while the northwest (small area of Ardabil province) and a few pixels in the central part show positive trends.

In general, spatiotemporal investigation of the contribution of each season and month in annual precipitation indicated that small regions in central Iran have a significant upward trend in spring, particularly in March. In addition, there are significant upward trends in summer and fall over a different part of Iran, including Zagros Mountain and northeast of Iran in summer (especially in June and July) and over south-eastern regions during the fall (especially in November). However, trends of contribution of season to annual precipitation, except for fall, do not have a significant effect on the seasonal precipitation. In addition, the contribution of any season to annual precipitation does not significantly shift to another season. Moreover, the results showed that the contribution of each season and month to annual precipitation in some parts of Iran varies between wet and dry years. The results indicated that precipitation that occurs over the eastern, northeast, and southwest regions of Iran during March, April, and December, respectively, could decrease in dry years.

Overall, the PERSIANN-CDR dataset with its relatively high spatial and temporal resolution covering nearly four decades proves to be a useful dataset for spatiotemporal investigation of precipitation, especially over regions like Iran with sparse spatial distribution of rain gauges.

Author Contributions: Conceptualization, methodology, and formal analysis, H.M., M.S., N.H., V.A.G., and A.A.A.; writing—original draft preparation, H.M. and M.S.; writing—review and editing, N.H., V.A.G., A.A.A., P.N., and S.S.; visualization, M.S. and H.M.; project administration, H.M.; funding acquisition, S.S. The authors would like to thank the reviewers and editors for their valuable comments. All authors have read and agreed to the published version of the manuscript.

Funding: This research was partially supported by Cooperative Institute for Climate and Satellites (CICS) program (NOAA Prime Award \#NA14NES4320003), and California Energy Commission (CEC Award \# 300-15-005).

Acknowledgments: The authors appreciate the anonymous reviewer for useful comments and suggestions. This research was conducted when the first author was a visiting graduate student at the Centre for Hydrometeorology and Remote Sensing at University of California, Irvine.

Conflicts of Interest: The authors declare no conflict of interest.

\section{References}

1. Wu, P.; Christidis, N.; Stott, P. Anthropogenic impact on Earth's hydrological cycle. Nat. Clim. Chang. 2013, 3, 807-810. [CrossRef] 
2. Tabari, H.; Aghajanloo, M.B. Temporal pattern of aridity index in Iran with considering precipitation and evapotranspiration trends. Int. J. Climatol. 2013, 33, 396-409. [CrossRef]

3. Madani, K.; AghaKouchak, A.; Mirchi, A. Iran's socio-economic drought: Challenges of a water-bankrupt nation. Iran. Stud. 2016, 49, 997-1016. [CrossRef]

4. Vaghefi, S.A.; Keykhai, M.; Jahanbakhshi, F.; Sheikholeslami, J.; Ahmadi, A.; Yang, H.; Abbaspour, K.C. The future of extreme climate in Iran. Sci. Rep. 2019, 9, 1-11. [CrossRef] [PubMed]

5. Dore, M.H. Climate change and changes in global precipitation patterns: What do we know? Environ. Int. 2005, 31, 1167-1181. [CrossRef]

6. Greve, P.; Orlowsky, B.; Mueller, B.; Sheffield, J.; Reichstein, M.; Seneviratne, S.I. Global assessment of trends in wetting and drying over land. Nat. Geosci. 2014, 7, 716-721. [CrossRef]

7. Nguyen, P.; Thorstensen, A.; Sorooshian, S.; Hsu, K.; Aghakouchak, A.; Ashouri, H.; Tran, H.; Braithwaite, D. Global precipitation trends across spatial scales using satellite observations. Bull. Am. Meteorol. Soc. 2018, 99, 689-697. [CrossRef]

8. $\quad$ Ma, Z.; Xu, Y.; Peng, J.; Chen, Q.; Wan, D.; He, K.; Shi, Z.; Li, H. Spatial and temporal precipitation patterns characterized by TRMM TMPA over the Qinghai-Tibetan plateau and surroundings. Int. J. Remote Sens. 2018, 39, 3891-3907. [CrossRef]

9. Belay, A.S.; Fenta, A.A.; Yenehun, A.; Nigate, F.; Tilahun, S.A.; Moges, M.M.; Dessie, M.; Adgo, E.; Nyssen, J.; Chen, M. Evaluation and Application of Multi-Source Satellite Rainfall Product CHIRPS to Assess Spatio-Temporal Rainfall Variability on Data-Sparse Western Margins of Ethiopian Highlands. Remote Sens. 2019, 11, 2688. [CrossRef]

10. Raja, N.B.; Aydin, O. Trend analysis of annual precipitation of Mauritius for the period 1981-2010. Meteorol. Atmos. Phys. 2019, 131, 789-805. [CrossRef]

11. Banerjee, A.; Chen, R.; E Meadows, M.; Singh, R.; Mal, S.; Sengupta, D. An Analysis of Long-Term Rainfall Trends and Variability in the Uttarakhand Himalaya Using Google Earth Engine. Remote Sens. 2020, 12, 709. [CrossRef]

12. Sadeghi, M.; Asanjan, A.A.; Faridzad, M.; Nguyen, P.; Hsu, K.; Sorooshian, S.; Braithwaite, D. PERSIANN-CNN: Precipitation Estimation from Remotely Sensed Information Using Artificial Neural Networks-Convolutional Neural Networks. J. Hydrometeorol. 2019, 20, 2273-2289. [CrossRef]

13. Guo, B.; Zhang, J.; Meng, X.; Xu, T.; Song, Y. Long-term spatio-temporal precipitation variations in China with precipitation surface interpolated by ANUSPLIN. Sci. Rep. 2020, 10, 1-17. [CrossRef] [PubMed]

14. Ashouri, H.; Hsu, K.-L.; Sorooshian, S.; Braithwaite, D.K.; Knapp, K.R.; Cecil, L.D.; Nelson, B.R.; Prat, O.P. PERSIANN-CDR: Daily precipitation climate data record from multisatellite observations for hydrological and climate studies. Bull. Am. Meteorol. Soc. 2015, 96, 69-83. [CrossRef]

15. Hsu, K.-1.; Gao, X.; Sorooshian, S.; Gupta, H.V. Precipitation estimation from remotely sensed information using artificial neural networks. J. Appl. Meteorol. 1997, 36, 1176-1190. [CrossRef]

16. Sorooshian, S.; Hsu, K.-L.; Gao, X.; Gupta, H.V.; Imam, B.; Braithwaite, D. Evaluation of PERSIANN system satellite-based estimates of tropical rainfall. Bull. Am. Meteorol. Soc. 2000, 81, 2035-2046. [CrossRef]

17. Sadeghi, M.; Akbari Asanjan, A.; Faridzad, M.; Afzali Gorooh, V.; Nguyen, P.; Hsu, K.; Sorooshian, S.; Braithwaite, D. Evaluation of PERSIANN-CDR Constructed Using GPCP V2. 2 and V2. 3 and A Comparison with TRMM 3B42 V7 and CPC Unified Gauge-Based Analysis in Global Scale. Remote Sens. 2019, 11, 2755. [CrossRef]

18. Arvor, D.; Funatsu, B.M.; Michot, V.; Dubreuil, V. Monitoring rainfall patterns in the southern amazon with PERSIANN-CDR data: Long-term characteristics and trends. Remote Sens. 2017, 9, 889. [CrossRef]

19. Chen, F.; Gao, Y. Evaluation of precipitation trends from high-resolution satellite precipitation products over Mainland China. Clim. Dyn. 2018, 51,3311-3331. [CrossRef]

20. Sobral, B.S.; de Oliveira-Júnior, J.F.; Alecrim, F.; Gois, G.; Muniz-Júnior, J.G.; de Bodas Terassi, P.M.; Pereira-Júnior, E.R.; Lyra, G.B.; Zeri, M. PERSIANN-CDR based characterization and trend analysis of annual rainfall in Rio De Janeiro State, Brazil. Atmos. Res. 2020, 238, 104873. [CrossRef]

21. Guo, H.; Bao, A.; Liu, T.; Chen, S.; Ndayisaba, F. Evaluation of PERSIANN-CDR for meteorological drought monitoring over China. Remote Sens. 2016, 8, 379. [CrossRef]

22. Zambrano, F.; Wardlow, B.; Tadesse, T.; Lillo-Saavedra, M.; Lagos, O. Evaluating satellite-derived long-term historical precipitation datasets for drought monitoring in Chile. Atmos. Res. 2017, 186, 26-42. [CrossRef] 
23. Lai, C.; Zhong, R.; Wang, Z.; Wu, X.; Chen, X.; Wang, P.; Lian, Y. Monitoring hydrological drought using long-term satellite-based precipitation data. Sci. Total Environ. 2019, 649, 1198-1208. [CrossRef] [PubMed]

24. Zhao, H.; Ma, Y. Evaluating the Drought-Monitoring Utility of Four Satellite-Based Quantitative Precipitation Estimation Products at Global Scale. Remote Sens. 2019, 11, 2010. [CrossRef]

25. Bai, X.; Wu, X.; Wang, P. Blending long-term satellite-based precipitation data with gauge observations for drought monitoring: Considering effects of different gauge densities. J. Hydrol. 2019, 577, 124007. [CrossRef]

26. Bai, X.; Shen, W.; Wu, X.; Wang, P. Applicability of long-term satellite-based precipitation products for drought indices considering global warming. J. Environ. Manag. 2020, 255, 109846. [CrossRef]

27. Katiraie-Boroujerdy, P.-S.; Ashouri, H.; Hsu, K.-1.; Sorooshian, S. Trends of precipitation extreme indices over a subtropical semi-arid area using PERSIANN-CDR. Theor. Appl. Climatol. 2017, 130, 249-260. [CrossRef]

28. Alijanian, M.; Rakhshandehroo, G.R.; Mishra, A.K.; Dehghani, M. Evaluation of satellite rainfall climatology using CMORPH, PERSIANN-CDR, PERSIANN, TRMM, MSWEP over Iran. Int. J. Climatol. 2017, 37, 4896-4914. [CrossRef]

29. Khalighi-Sigaroodi, S.; Ghaljaee, E.; Moghaddamnia, A.; Malekian, A.; Zhang, F. Evaluation of TRMM-3B42v7 and PERSIANN-CDR daily-precipitation products for the southern slopes of Alborz mountains, Iran. In Proceedings of the International Archives of the Photogrammetry, Remote Sensing \& Spatial Information Sciences, Karaj, Iran, 12-14 October 2019.

30. Salmani-Dehaghi, N.; Samani, N. Spatiotemporal assessment of the PERSIANN family of satellite precipitation data over Fars Province, Iran. Theor. Appl. Climatol. 2019, 138, 1333-1357. [CrossRef]

31. Fallah, A.; Rakhshandehroo, G.R.; Berg, P.O.S.; Orth, R. Evaluation of precipitation datasets against local observations in Southwestern Iran. Int. J. Climatol. 2019. [CrossRef]

32. Mosaffa, H.; Shirvani, A.; Khalili, D.; Khalili, D.; Sorooshian, S. Post and near real-time satellite precipitation products skill over Karkheh River Basin in Iran. Int. J. Remote Sens. 2020. [CrossRef]

33. Miri, M.; Masoudi, R.; Raziei, T. Performance Evaluation of Three Satellites-Based Precipitation Data Sets Over Iran. J. Indian Soc. Remote Sens. 2019, 47, 2073-2084. [CrossRef]

34. Hosseini-Moghari, S.M.; Araghinejad, S.; Ebrahimi, K. Spatio-temporal evaluation of global gridded precipitation datasets across Iran. Hydrol. Sci. J. 2018, 63, 1669-1688. [CrossRef]

35. Alijanian, M.; Rakhshandehroo, G.R.; Mishra, A.; Dehghani, M. Evaluation of remotely sensed precipitation estimates using PERSIANN-CDR and MSWEP for spatio-temporal drought assessment over Iran. J. Hydrol. 2019, 579, 124189. [CrossRef]

36. Raziei, T.; Daryabari, J.; Bordi, I.; Modarres, R.; Pereira, L.S. Spatial patterns and temporal trends of daily precipitation indices in Iran. Clim. Chang. 2014, 124, 239-253. [CrossRef]

37. Balling, R.C.; Keikhosravi Kiany, M.S.; Sen Roy, S.; Khoshhal, J. Trends in extreme precipitation indices in Iran: 1951-2007. Adv. Meteorol. 2016, 2016, 2456809. [CrossRef]

38. Khalili, K.; Tahoudi, M.N.; Mirabbasi, R.; Ahmadi, F. Investigation of spatial and temporal variability of precipitation in Iran over the last half century. Stoch. Environ. Res. Risk Assess. 2016, 30, 1205-1221. [CrossRef]

39. Modarres, R.; da Silva, V.d.P.R. Rainfall trends in arid and semi-arid regions of Iran. J. Arid Environ. 2007, 70, 344-355. [CrossRef]

40. Tabari, H.; Talaee, P.H. Temporal variability of precipitation over Iran: 1966-2005. J. Hydrol. 2011, 396, 313-320. [CrossRef]

41. Kousari, M.R.; Ekhtesasi, M.R.; Tazeh, M.; Naeini, M.A.S.; Zarch, M.A.A. An investigation of the Iranian climatic changes by considering the precipitation, temperature, and relative humidity parameters. Theor. Appl. Climatol. 2011, 103, 321-335. [CrossRef]

42. Tabari, H.; Somee, B.S.; Zadeh, M.R. Testing for long-term trends in climatic variables in Iran. Atmos. Res. 2011, 100, 132-140. [CrossRef]

43. Some'e, B.S.; Ezani, A.; Tabari, H. Spatiotemporal trends and change point of precipitation in Iran. Atmos. Res. 2012, 113, 1-12.

44. Soltani, S.; Saboohi, R.; Yaghmaei, L. Rainfall and rainy days trend in Iran. Clim. Chang. 2012, 110, $187-213$. [CrossRef]

45. Zarenistanak, M.; Dhorde, A.G.; Kripalani, R. Trend analysis and change point detection of annual and seasonal precipitation and temperature series over southwest Iran. J. Earth Syst. Sci. 2014, 123, 281-295. [CrossRef] 
46. Shirvani, A. Change in annual precipitation in the northwest of I ran. Meteorol. Appl. 2017, 24, $211-218$. [CrossRef]

47. Zarei, A.R.; Masoudi, M. Trend assessment of climate changes in Iran. EQA-Int. J. Environ. Qual. 2019, 34, $1-16$.

48. Knapp, K.R. Scientific data stewardship of International Satellite Cloud Climatology Project B1 global geostationary observations. J. Appl. Remote Sens. 2008, 2, 023548. [CrossRef]

49. Rossow, W.B.; Schiffer, R.A. ISCCP cloud data products. Bull. Am. Meteorol. Soc. 1991. [CrossRef]

50. Fulton, R.A.; Breidenbach, J.P.; Seo, D.-J.; Miller, D.A.; O'Bannon, T. The WSR-88D rainfall algorithm. Weather Forecast. 1998, 13, 377-395. [CrossRef]

51. Lin, Y.; Mitchell, K.E. 1.2 the NCEP stage II/IV hourly precipitation analyses: Development and applications. In Proceedings of the 19th Conference Hydrology, American Meteorological Society, San Diego, CA, USA, 9-13 January 2005.

52. Nguyen, P.; Shearer, E.J.; Tran, H.; Ombadi, M.; Hayatbini, N.; Palacios, T.; Huynh, P.; Braithwaite, D.; Updegraff, G.; Hsu, K. The CHRS Data Portal, an easily accessible public repository for PERSIANN global satellite precipitation data. Sci. Data 2019, 6, 1-10. [CrossRef]

53. McKee, T.B.; Doesken, N.J.; Kleist, J. The relationship of drought frequency and duration to time scales. In Proceedings of the 8th Conference on Applied Climatology, Anaheim, CA, USA, 17-22 January 1993; pp. 179-183.

54. Mann, H.B. Nonparametric tests against trend. Econom. J. Econom. Soc. 1945, 13, 245-259. [CrossRef]

55. Kendall, M. Rank Correlation Measures; Charles Griffin: London, UK, 1975; Volume 202, p. 15.

(C) 2020 by the authors. Licensee MDPI, Basel, Switzerland. This article is an open access article distributed under the terms and conditions of the Creative Commons Attribution (CC BY) license (http://creativecommons.org/licenses/by/4.0/). 